\title{
On Predicting Automotive Clutch Torsional Vibrations
}

\author{
T. Gkinis, R. Rahmani, H. Rahnejat \\ Wolfson School of Mechanical, Electrical and Manufacturing Engineering, Loughborough University, Leicestershire, UK
}

\begin{abstract}
Automotive clutches are prone to rigid body torsional vibrations during engagement, a phenomenon referred to as take-up judder. This is also accompanied by fore and aft vehicle motions. Aside from driver behaviour in sudden release of clutch pedal (resulting in loss of clamp load), and type and state of friction lining material, the interfacial slip speed and contact temperature can significantly affect the propensity of clutch to judder. The ability to accurately predict the judder phenomenon relies significantly on the determination of operational frictional characteristics of the clutch lining material. This is dependent upon contact pressure, temperature and interfacial slip speed. The current study investigates the ability to predict clutch judder vibration with the degree of complexity of the torsional dynamics model. For this purpose, the results from a four and nine degrees of freedom dynamics models are compared and discussed. Subsequently, the predictions are compared with the acquired data from an automotive driveline test rig. It is shown that the complexity of the dynamic model, intended for the study of a clutch system, can be as important as the thermo-mechanical and frictional properties of the clutch friction lining material.
\end{abstract}

Keywords: Dry automotive clutch; Torsional vibrations; Clutch judder; Friction

\section{Introduction}

Low frequency torsional rigid body dynamic vibrations of automotive clutch systems during engagement are known as clutch take-up judder vibrations. These vibrations occur in the frequency range 5$20 \mathrm{~Hz}$ for most vehicles. It can also lead to fore and aft oscillations of the vehicle body, which can be quite disconcerting to the vehicle occupants [1]. An early investigation of this phenomenon was carried out by Jarvis and Mills [2] and later by Maucher [3], both concluding that frictional properties of the clutch lining material have a significant influence in inducing judder type motions of the vehicle. It is also shown that the thermoelastic distortion of contacting surfaces, existence of misalignment in the drivetrain, engine torque fluctuations and loss of clutch clamp load with hurried release of clutch pedal are other contributing factors to clutch judder [4-7]. Centea et al [8-9] showed that a negative slope of coefficient of friction variation with the interfacial slip speed promotes judder with a greater degree of severity.

Crowther et al in [10] developed a simple lumped parameter dynamic model to examine clutch judder vibrations, whilst in [11] they developed a six degree of freedom dynamic model, including an automatic transmission, differential gearing and the driveline. They

Page 1 of 6 reported longitudinal vehicle vibration resulting from misalignment of the driveline, which is a major source of judder. They also highlighted the significance of clutch friction lining. Gkinis et al [12] used a 4-degrees of freedom model to study clutch judder vibrations using measured friction coefficients from actual clutch lining material at various operating temperatures [13]. The conditions used in pinon-disc tribometry were representative of contact pressure and temperatures experienced in clutches in real application. The results indicated a greater propensity to judder at lower bulk clutch face temperatures. Observing the importance of contact temperature on the frictional behaviour of lining material in [12], Gkinis et al [14] used a thermal network model to predict the rise in the contact temperature for both new and used clutch lining materials during a typical engagement process. They also measured the required thermal transport properties of both new and worn lining materials. Recently, a combined thermal and dynamic model of the clutch system is presented by Gkinis et al [15], where a strong relationship between powertrain NVH (Noise, Vibration and Harshness) phenomenon such as judder and system thermal performance was observed, one which had not hitherto been reported in the literature. It was observed that the measured coefficient of friction for the used lining material is approximately $20 \%$ lower than that of a new one. The results also showed that the coefficient of friction of the clutch lining material has a larger effect on clutch contact temperature rise than the thermal properties of the lining material.

The current study aims at a combined experimental and numerical study of the clutch judder phenomenon, using the actual measured data for the clutch lining material. It highlights the importance of a developed dynamic model and depth of detail in more accurate prediction of the judder phenomenon.

\section{Methodology}

\section{Numerical Model}

Two dynamic models for the evaluation of clutch torsional vibrations are presented; one is the commonly used simple 4-DOF of model (Figure 1a) and the other is the more detailed 9-DOF model (Figure 1b). In the 4-DOF model, the inertial elements include the engine $\left(\mathrm{I}_{1}\right)$, combined flywheel and friction disc $\left(\mathrm{I}_{2}\right)$, friction disc and pressure plate $\left(\mathrm{I}_{3}\right)$ and the entire vehicle inertia, including the remainder of the drivetrain system $\left(\mathrm{I}_{4}\right)$. In this model the engine/flywheel and the clutch input are connected through an equivalent shaft, representative of the crankshaft, with known stiffness and damping. A similar provision is made for the output part of the clutch and the vehicle drivetrain. The equations of motion, are given in the form: 


$$
[I]\{\ddot{\theta}\}+[C]\{\dot{\theta}\}+[K]\{\theta\}=\{T\}
$$

where inertia, damping and stiffness matrices, as well as the torque vector are:

$$
\begin{aligned}
& {[I]=\left[\begin{array}{cccc}
I_{1} & 0 & 0 & 0 \\
0 & I_{2} & 0 & 0 \\
0 & 0 & I_{3} & 0 \\
0 & 0 & 0 & I_{4}
\end{array}\right],[C]=\left[\begin{array}{cccc}
c_{1} & -c_{1} & 0 & 0 \\
-c_{1} & c_{1} & 0 & 0 \\
0 & 0 & c_{2} & -c_{2} \\
0 & 0 & -c_{2} & c_{2}
\end{array}\right],[K]=} \\
& {\left[\begin{array}{cccc}
k_{1} & -k_{1} & 0 & 0 \\
-k_{1} & k_{1} & 0 & 0 \\
0 & 0 & k_{2} & -k_{2} \\
0 & 0 & -k_{2} & k_{2}
\end{array}\right],\{T\}=\left\{\begin{array}{c}
T_{e} \\
-T_{f} \\
T_{f} \\
T_{r}
\end{array}\right\}}
\end{aligned}
$$

As clutch engagement occurs, the inertial elements ( $\mathrm{I}_{2}$ and $\left.\mathrm{I}_{3}\right)$ combine, therefore the system reduces to a 3-DOF model. Further details for this developed dynamic model can be found in [12].

In the more detailed 9-DOF dynamic model (Figure 1b), the engine is represented by the inertial element $\left(\mathrm{I}_{1}\right)$, whilst the second and third inertial elements $\left(\mathrm{I}_{2}\right.$ and $\left.\mathrm{I}_{3}\right)$ represent the flywheel and the friction disc respectively. Furthermore, the fourth and fifth inertial elements $\left(\mathrm{I}_{4}\right.$ and $\left.\mathrm{I}_{5}\right)$ are those of the gearbox. The sixth and seventh inertial components ( $\mathrm{I}_{6}$ and $\mathrm{I}_{7}$ ) are for that of the differential unit. Inertial elements $\mathrm{I}_{8}$ and $\mathrm{I}_{10}$ represent the left and right rear axle half-shafts in this rear wheel drive system, whilst $\mathrm{I}_{9}$ and $\mathrm{I}_{11}$ inertial elements are those of the left road wheel and half vehicle, and the right road wheel and half vehicle respectively. In this model the corresponding inertia, damping and stiffness matrices are given as:

$[I]=\left[\begin{array}{ccccccccc}I_{1} & 0 & 0 & 0 & 0 & 0 & 0 & 0 & 0 \\ 0 & I_{2} & 0 & 0 & 0 & 0 & 0 & 0 & 0 \\ 0 & 0 & I_{3} & 0 & 0 & 0 & 0 & 0 & 0 \\ 0 & 0 & 0 & \left(I_{4} n_{1}^{2}+I_{5}\right) & 0 & 0 & 0 & 0 & 0 \\ 0 & 0 & 0 & 0 & \left(I_{6} n_{2}^{2}+I_{7}\right) & 0 & 0 & 0 & 0 \\ 0 & 0 & 0 & 0 & 0 & I_{8} & 0 & 0 & 0 \\ 0 & 0 & 0 & 0 & 0 & 0 & I_{9} & 0 & 0 \\ 0 & 0 & 0 & 0 & 0 & 0 & 0 & I_{10} & 0 \\ 0 & 0 & 0 & 0 & 0 & 0 & 0 & 0 & I_{11}\end{array}\right](3)$

$[C]=$
$\left[\begin{array}{ccccccccc}c_{1} & -c_{1} & 0 & 0 & 0 & 0 & 0 & 0 & 0 \\ -c_{1} & c_{1} & 0 & 0 & 0 & 0 & 0 & 0 & 0 \\ 0 & 0 & c_{2} & -n_{1} c_{2} & 0 & 0 & 0 & 0 & 0 \\ 0 & 0 & n_{1} c_{2} & n_{1}^{2} c_{2}+c_{3} & -n_{2} c_{3} & 0 & 0 & 0 & 0 \\ 0 & 0 & 0 & -n_{2} c_{3} & n_{2}^{2} c_{3}+c_{4}+c_{6} & -c_{4} & 0 & -c_{6} & 0 \\ 0 & 0 & 0 & 0 & -c_{4} & c_{4}+c_{5} & -c_{5} & 0 & 0 \\ 0 & 0 & 0 & 0 & 0 & -c_{5} & c_{5} & 0 & 0 \\ 0 & 0 & 0 & 0 & -c_{6} & 0 & 0 & c_{6}+c_{7} & -c_{7} \\ 0 & 0 & 0 & 0 & 0 & 0 & 0 & -c_{7} & c_{7}\end{array}\right]$ (4)

$[K]==$
$\left[\begin{array}{ccccccccc}k_{1} & -k_{1} & 0 & 0 & 0 & 0 & 0 & 0 & 0 \\ -k_{1} & k_{1} & 0 & 0 & 0 & 0 & 0 & 0 & 0 \\ 0 & 0 & k_{2} & -n_{1} k_{2} & 0 & 0 & 0 & 0 & 0 \\ 0 & 0 & n_{1} k_{2} & n_{1}^{2} k_{2}+k_{3} & -n_{2} k_{3} & 0 & 0 & 0 & 0 \\ 0 & 0 & 0 & -n_{2} k_{3} & n_{2}^{2} k_{3}+k_{4}+k_{6} & -k_{4} & 0 & -k_{6} & 0 \\ 0 & 0 & 0 & 0 & -k_{4} & k_{4}+k_{5} & -k_{5} & 0 & 0 \\ 0 & 0 & 0 & 0 & 0 & -k_{5} & k_{5} & 0 & 0 \\ 0 & 0 & 0 & 0 & -k_{6} & 0 & 0 & k_{6}+k_{7} & -k_{7} \\ 0 & 0 & 0 & 0 & 0 & 0 & 0 & -k_{7} & k_{7}\end{array}\right](5)$

Upon fully engaged conditions, the equations of motion take the form of an 8-DOF system. Further details of the developed dynamic model can be found in [14].

Page 2 of 6

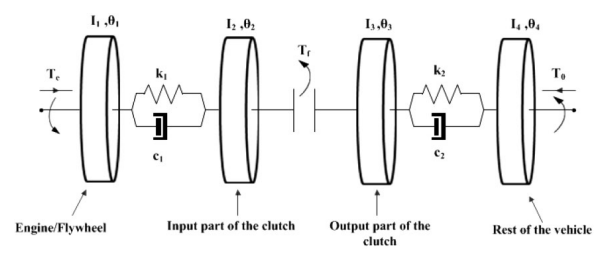

(a)

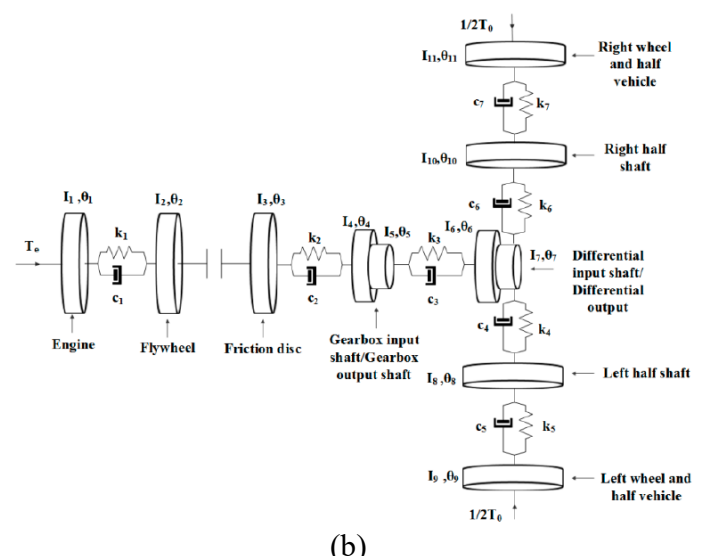

Figure 1: a (a) four and (b) nine degree of freedom clutch dynamic model

In these models, the proportional damping approach is used for calculating the damping coefficient, in which it is assumed that the system is lightly damped and hence the damping is proportional to the stiffness by a factor: $\beta=2 \zeta_{n} / \omega_{n}$.

The engine, resistive and frictional torques are [12]:

$$
\begin{aligned}
& T_{e}=T_{m}+\sum_{n} T_{p n} \sin \left(n \omega_{e} t+\varphi_{p n}\right) \\
& T_{r}=R_{w}\left(\mu_{r} W_{v}+\frac{1}{2} d_{a} V^{2} C_{d} A\right) \\
& T_{f}= \begin{cases}\frac{2}{3} \mu \frac{r_{o}^{3}-r_{i}^{3}}{r_{o}^{2}-r_{i}^{2}} F_{n} & \text { if }\left(\omega_{d}-\omega_{p}\right)>0 \\
-\frac{2}{3} \mu \frac{r_{o}^{3}-r_{i}^{3}}{r_{o}^{2}-r_{i}^{2}} F_{n} & \text { if }\left(\omega_{d}-\omega_{p}\right)<0 \\
0 & \text { if }\left(\omega_{d}-\omega_{p}\right)=0\end{cases}
\end{aligned}
$$

where, $\omega_{d}$ and $\omega_{p}$ are the angular velocities of the clutch disc and the pressure plate respectively.

\section{Experimental Measurements}

\section{Measurement of Coefficient of Friction}

A key parameter influencing clutch judder is the interfacial coefficient of friction, $\mu$, between the lining material and the flywheel and its variation with relative slip speed, clamp load and contact temperature. Furthermore, lining material operational age also plays an important role due to usage wear and depletion of lining material constituents. Humphrey et al [13] conducted an extensive tribological examination of the new and worn friction lining material properties under various operational conditions. Figure 2 shows the pin-on-disc tribometer used with its surface heating element, enabling measurement of friction at higher temperatures. 


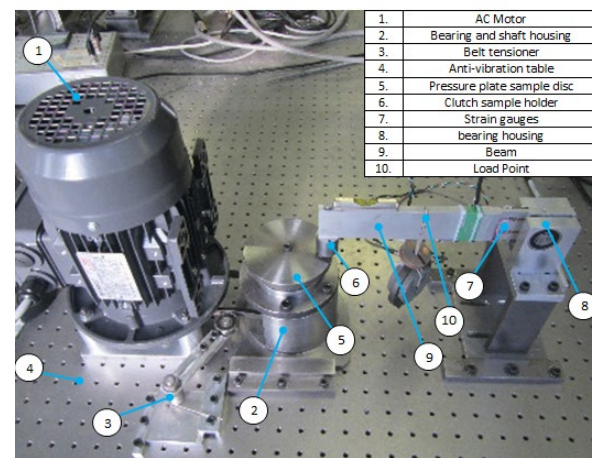

(a)

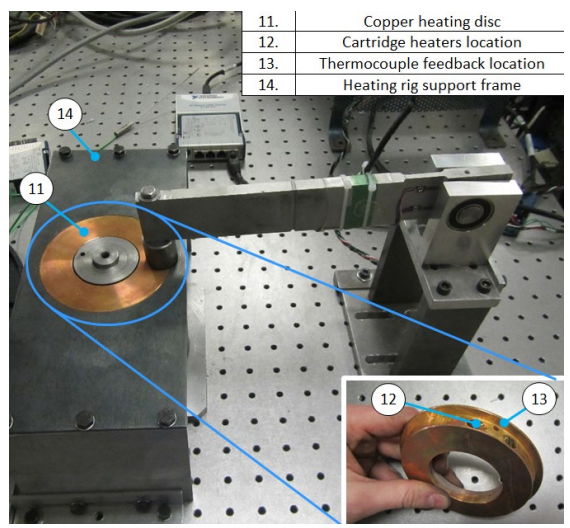

(b)

Figure 2: (a) The pin-on-disc tribometer and (b) the heating system

Tables 1 lists the extrapolated relationships obtained for measured coefficient of friction versus relative slip speed at different operating temperatures, for new and used clutch lining materials. The worn clutch lining material was taken from a real worn clutch system after $50,000 \mathrm{~km}$ use.

Table 1: Extrapolated relationships for variation of coefficient of friction for the new and worn clutch lining materials with slip speed, $v$, at different temperatures [14]

\begin{tabular}{ccc}
\hline Temperature & New lining material & Worn lining material \\
\hline $\mathbf{2 0}{ }^{\circ} \mathrm{C}$ & $0.48-0.021 v$ & $0.32-0.00189 v$ \\
$\mathbf{4 0}$ & $0.49-0.0191 v$ & $0.32-0.00452 v$ \\
$\mathbf{6 0}^{\circ} \mathrm{C}$ & $0.48-0.0178 v$ & $0.31-0.00761 v$ \\
$\mathbf{9 0}^{\circ} \mathrm{C}$ & $0.47-0.0167 v$ & $0.34-0.00436 v$ \\
\hline
\end{tabular}

\section{Measurement of Clutch Judder Vibrations}

The powertrain rig used is shown in Figure 3, comprising an electric motor and an inverter drive control system, a clutch actuation system, a 4-speed transmission, a 3-piece driveshaft, a differential, and rear axle half-shafts. This is the drivetrain system for a long wheel-base rear wheel drive light truck.

Page 3 of 6

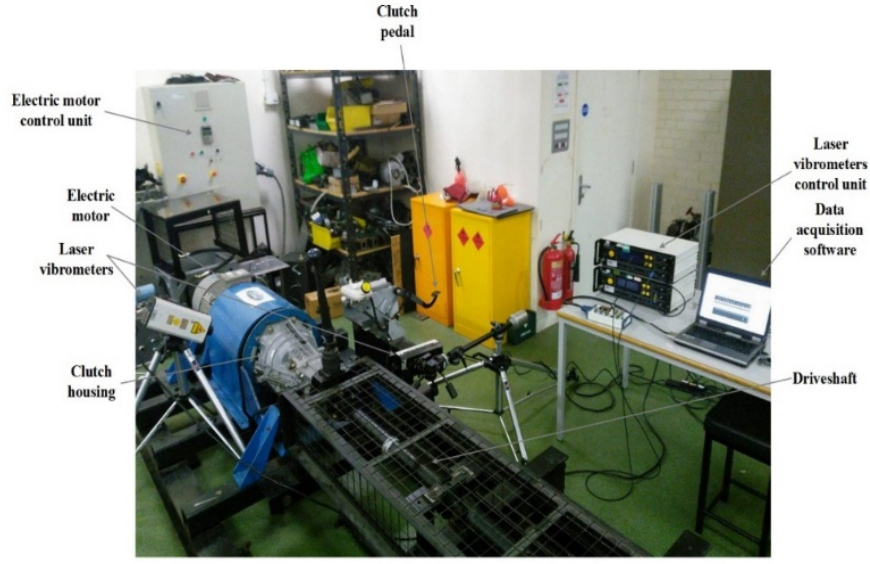

Figure 3: Vehicle powertrain rig used for the measurement of torsional vibrations

The electric motor provides controllable input torque representative of those by an internal combustion engine. The IMO controller also introduces $2^{\text {nd }}$ engine order equivalent input at $10 \%$ of the nominal transmission input shaft speed. The motor is directly coupled to the flywheel using a flexible coupling between the motor and the flywheel. In addition, a standard vehicle manual hydraulic clutch actuation system is used. The actuation system is designed with the repeatability of the experimental measurements in mind, therefore utilising a clutch pedal mounted accelerometer.

Laser vibrometers were used to measure the angular velocities of the driveshaft tubes and the flywheel including the fluctuations in the angular velocity of the shafts during clutch engagement which can be considered as indicative of clutch judder.

\section{Results and Discussion}

Laser vibrometers were pointed at the flywheel surface and the output shaft of the transmission to monitor vibration. LabView software was used for real time data acquisition and processing. The measurements were intended to monitor clutch shift from idle to first gear, with the engagement often subject to take-up judder. The inverter control was used to set the motor speed, representative of idle operating conditions for the light truck powertrain under investigation [8]. For the numerical simulations, detailed input data can be found in $[12,15]$.

Figure 4a shows the variation of measured angular velocity of the flywheel during clutch engagement as acquired by the laser vibrometer. It can be seen that the clutch engagement takes place at around the $0.1 \mathrm{sec}$ post actuation, when a sudden (approximately 9\%) drop in the flywheel angular velocity is recorded. 


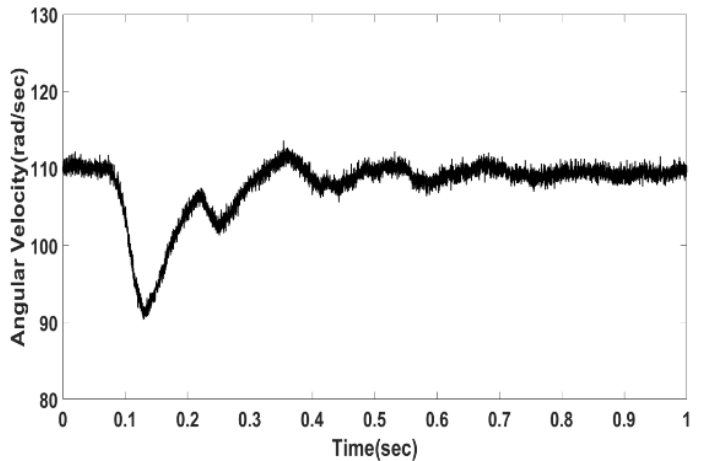

(a)

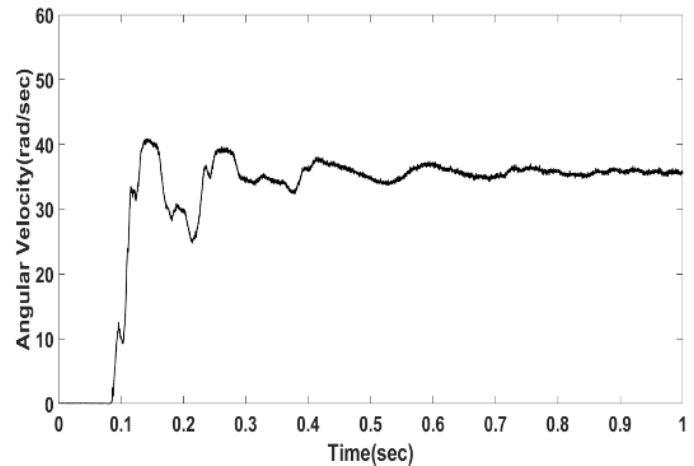

(b)

Figure 4: Measured variation in angular velocity of (a) flywheel and (b) driveshaft during clutch engagement

Figure $4 \mathrm{~b}$ shows the variation in the driveshaft angular velocity during clutch engagement. As it can be seen, there is a series of oscillations in the angular velocity profile. An analysis of the main fluctuations indicates a frequency range below $20 \mathrm{~Hz}$, which is an indication of clutch judder [8]. It is important to note that although judder is induced by stick-slip friction, certain elements of an actual vehicle can affect the actual measured amplitude and intensity. In addition, use of an electric motor instead of an internal combustion engine lacks proper representation of the entire complex engine order vibrations [16]. Additionally, no vehicle inertia and resisting torque exist in the current design of the rig. Furthermore, the rear axle is rigidly clamped to the ground. Therefore, no fore and aft shuffle-type behaviour as in a real vehicle is allowed.

Figure 5 shows the predicted angular velocity profile of the driveshaft, based on the two developed dynamic models. The input data for the 4-DoF and 9-DoF models can be found in [12] and [15], respectively. The two time-histories appear to be quite similar, particularly in terms of the final steady state angular velocity, which is close to the measurement shown in Figure 4b. However, it is quite clear that there are significant differences. As it would be expected the dynamic model with the higher degree of freedom (Figure $5 \mathrm{~b}$ ) provides a more realistic outcome, when compared with the measured results in Figure $4 b$.

As already noted, the angular velocity is measured at the output transmission shaft. Therefore, the gear ratio 3 can be seen in the reduced mean output velocity in Figure $5 \mathrm{~b}$. After the initial engagement, it can be seen from Figure $5 b$ that the angular velocity oscillates around $35 \mathrm{rad} / \mathrm{sec}$ base line for about $0.5 \mathrm{sec}$ which represents the duration of the clutch engagement.

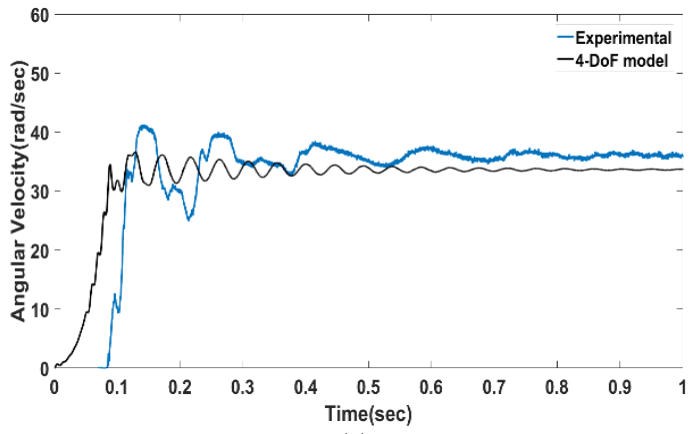

(a)

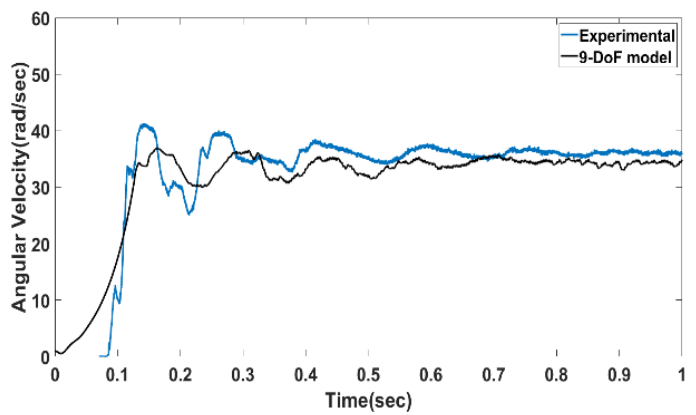

(b)

Figure 5: Predicated angular velocity profile of the driveshaft during clutch engagement based on (a) 4 DOF and (b) 9 DOF dynamic models

Figure 6 shows the results of continuous wavelet time-frequency analysis on the measured and predicted angular velocity fluctuations of the driveshaft from Figures $4 \mathrm{~b}$ and $5 \mathrm{~b}$. Figure $6 \mathrm{a}$ shows that the main frequencies contributions occur in the band: $5-10 \mathrm{~Hz}$, which is indicative of judder vibrations. Note that vehicle shuffle does not occur due to the rigid constraining of the rear axle. Figure $6 \mathrm{~b}$ shows the continuous wavelet spectrum of the predicted angular velocity variation by the 9 -DOF model during clutch engagement from idle to first gear selection. In the wavelet spectrum of Figure $6 \mathrm{~b}$, the spectral content is mainly in the range $15-20 \mathrm{~Hz}$. The low frequency vibrations seen above are signature of judder vibrations as they only occur duration clutch engagement.

It should be noted that for the 9-DOF model validation simulation were run for the conditions pertaining to the operation of the experimental set up. The coefficient of friction for the new clutch material, measured at $20^{\circ} \mathrm{C}$, was used as an input into the model. Since the clutch engagement with the rig occurs in a very short period of time, ambient temperature of $20^{\circ} \mathrm{C}$ is considered to be a good representation of the laboratory conditions. 


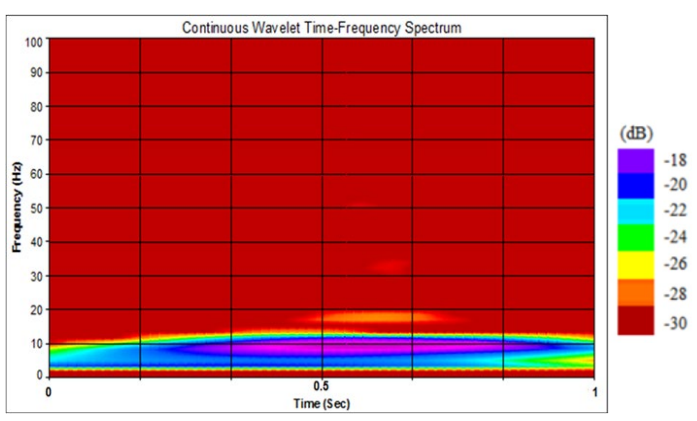

(a)

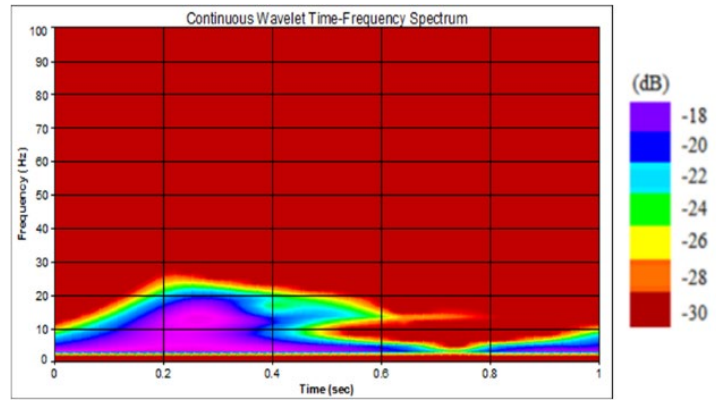

(b)

Figure 6: Continuous wavelet analysis of the angular velocity variations of the driveshaft during engagement: (a) experimental and (b) extended 9DoF dynamic model

Comparing the results in Figures $6 \mathrm{a}$ and $6 \mathrm{~b}$ shows that the main frequencies in Figure 6a, based on measurements, are shifted by $10 \mathrm{~Hz}$ above those predicted in Figure 6b. This can be attributed to additional damping elements in the gearbox that cannot be measured directly and thus, are not included in the current system model. Furthermore, additional frequencies in Figure 6a are located at around $35 \mathrm{~Hz}$. These frequencies show a considerably shorter bandwidth and may be attributed to localised impacts in the manual clutch engagement process which occurs in short durations. However, such effects were not included in the current modelling approach.

\section{Conclusions}

Experimental measurements of angular velocity of driveshaft of a rear-wheel drive long wheel-base light truck drivetrain were conducted using laser Doppler vibrometry. Clutch engagement was measured from idle to first gear engagement to capture the take-up judder phenomenon. In addition, two dynamic models; a 4-DOF model commonly reported commonly in literature, and a more detailed 9-DOF model were developed to also investigate their suitability to predict clutch take-up judder. Furthermore, specific coefficients of friction for the clutch lining materials and their variation with interfacial slip speed and contact temperature were obtained using pin-on-disc tribometry.

The experimentally acquired data presented a clear indication of judder vibrations during clutch engagement. The strong presence of frequencies around $10 \mathrm{~Hz}$ is observed for the duration of clutch engagement. Additional higher frequencies with shorter durations and lower intensity were also observed.

The extended 9-DOF tribodynamics model was run for the case of new (unused) clutch material with a coefficient of friction measured experimentally at $20^{\circ} \mathrm{C}$. The predictions from the extended dynamic model indicated that the predicted amplitudes of vibrations in the extended model are smaller than those from the simpler less detailed 4-DOF one. This is because of the introduction of additional inertial and damping elements. Thus, the simpler dynamic models are prone to produce unrealistic and sometimes exaggerated vibration signatures attributed to judder when studying clutch vibrations. As expected, better agreement between the predictions of the detailed dynamic model and those measured experimentally were observed. However, it was not possible to capture the higher frequency impactinduced engagement vibrations seen in the measured data. It was also observed that the predicted frequencies of the torsional vibrations close to full engagement are shifted to a slightly lower region of the spectrum in the extended model. This may be attributed to an overestimation of damping in the model, leading to lower frequency responses. Consequently, to study such effects a conjugate dynamic model, taking into account the axial vibrations of the clutch and drivetrain system should be developed.

\section{References}

1. Drexl, H., "Clutch judder-causes and counter measures", In Proc. Tech. Conf. SITEV., 1990, pp. 7-46

2. Jarvis, R. P. and Mills, B., "Vibrations induced by dry friction", Proc. IMechE, 1963-4, 178(32), pp. 847-866

3. Maucher, P., "Clutch chatter", In Proc. $4^{\text {th }}$ Int. sympos. on Torsional Vibrations in the Drive train, Baden-Baden, Germany, 1990

4. Bostwick, C.C., Corp, C. and Corp, E., "Self-excited vibrations during engagements of dry friction clutches, Engineering, 1998, (724)

5. Rabeih, E.M.A. and Crolla, D.A., "Intelligent control of clutch judder and shunt phenomena in vehicle drivelines", Int. J. Veh. Des., 1996, 17(3), pp.318-332

6. Yang, L.K., Li, H.Y., Ahmadian, M. and Ma, B., "Analysis of the influence of engine torque excitation on clutch judder", J, Vibration and Control, 2017, 23(4), pp. 645-655

7. Menday, M.T. and Rahnejat, H., "Friction lining characteristics and the clutch take up judder phenomenon with manual transmission", In: Rahnejat, H. (ed). Tribology and Dynamics of Engine and Powertrain: Fundamentals, Applications and Future Trends, Woodhead Publishing Ltd, Cambridge, 2010, pp. 680 - 702

8. Centea, D., Rahnejat, H. and Menday, M.T., "Non-linear multi-body dynamic analysis for the study of clutch torsional vibrations (judder)", Applied Mathematical Modelling, 2001, 25(3), pp.177-192

9. Centea, D., Rahnejat, H. and Menday, M.T., "The influence of the interface coefficient of friction upon the propensity to judder in automotive clutches", Proc.IMechE, Part D: J. Automobile Engineering, 1999, 213(3), pp.245-258

10. Crowther, A., Zhang, N., Liu, D.K. and Jeyakumaran, J.K., "Analysis and simulation of clutch engagement judder and stick-slip in automotive powertrain systems", Proc. IMechE, Part D: J. Automobile Engineering, 2004, 218(12), pp. 14271446

11. Crowther, A.R. and Zhang, N., 2005. "Torsional finite elements and nonlinear numerical modelling in vehicle

Page 5 of 6

$10 / 19 / 2016$ 
powertrain dynamics", J. Sound and Vibration, 2005, 284(35), pp.825-849

12. Gkinis, T., Rahmani, R. and Rahnejat, H., "Effect of clutch lining frictional characteristics on take-up judder", Proc. IMechE, Part K: J. Multi-body Dynamics, 2017, 231(3), pp. 493-503

13. Humphrey, E., Gkinis, T., Morris, N.J., Leighton, M., Rahmani, R. and Rahnejat, H., "Clutch lining frictional characteristics under thermal tribodynamic conditions", $3^{\text {rd }}$ Biennial Int. Conf. on Powertrain Modelling and Control (PMC 2016), Loughborough University, UK, 2016

14. Gkinis, T., Rahmani, R., Rahnejat, H. and O'Mahony, M., "Heat generation and transfer in automotive dry clutch engagement", J. Zhejiang University-SCIENCE A, 2018, 19(3), pp. 175-188

15. Gkinis, T., Rahmani, R. and Rahnejat, H., "Integrated thermal and dynamic analysis of dry automotive clutch linings", Applied Sciences, 2019, 9(20), pp. 4287

16. Rahnejat, H., "Multi-body Dynamics: Vehicles, machines and mechanisms", Professional Engineering Publishing, Bury St Edmunds, UK, 1998.

\section{Contact Information}

Dr Ramin Rahmani, Email. R.Rahmani@lboro.ac.uk, Tel: +44 1509 227669.

\section{Acknowledgements}

The authors would like to thank Ford motor company for the technical support of this research.

\section{Nomenclature}

A Effective vehicle frontal area

C Damping matrix

$C_{d} \quad$ Aerodynamic drag coefficient

$d_{a} \quad$ Density of air

$F_{n} \quad$ Normal (clamp) load

$\boldsymbol{K} \quad$ Stiffness matrix

I Inertia matrix

$n \quad$ Engine order harmonic number

$R_{w} \quad$ Laden wheel radius

$r_{i} \quad$ Inner radius

$\begin{array}{ll}r_{o} & \text { Outer radius } \\ \boldsymbol{T} & \text { Torque vector } \\ T_{e} & \text { Engine torque } \\ T_{f} & \text { Friction torque } \\ T_{m} & \text { Mean engine torque } \\ T_{p n} & \text { Pulsating engine torque } \\ T_{r} & \text { Resistive torque } \\ t & \text { Time } \\ V & \text { Vehicle velocity } \\ W_{v} & \text { Vehicle weight }\end{array}$

Greek symbols

$\beta \quad$ Scalar multiplier

$\zeta_{n} \quad$ Damping ratio of the $n^{\text {th }}$ mode

$\boldsymbol{\theta}$ Angular displacement vector

$\dot{\boldsymbol{\theta}} \quad$ Angular velocity vector

$\ddot{\boldsymbol{\theta}} \quad$ Angular acceleration vector

$\mu \quad$ Coefficient of friction

$\mu_{r} \quad$ Coefficient of rolling resistance

$\varphi_{p n} \quad$ Initial phase of the nth engine order

$\omega_{e} \quad$ Crankshaft angular velocity

$\omega_{d} \quad$ Angular velocity of clutch disc

$\omega_{n} \quad$ Natural frequency

$\omega_{p} \quad$ Angular velocity of pressure plate

\section{Abbreviations}

DoF degree of freedom

IMO IMO Precision Controls Ltd

NVH Noise, Vibration and Harshness 